\title{
圆 \\ Use of scanning electron microscopy to confirm the identity of lice infesting communally grazed goat herds
}

\author{
P.J. SEBEI ${ }^{1}$, C.M.E. MCCRINDLE ${ }^{1}$, E.D. GREEN ${ }^{2}$ and M.L. TURNER ${ }^{3}$
}

\begin{abstract}
SEBEI, P.J., McCRINDLE, C.M.E., GREEN, E.D. \& TURNER, M.L. 2004. Use of scanning electron microscopy to confirm the identity of lice infesting communally grazed goat herds. Onderstepoort Journal of Veterinary Research, 71:87-92

Lice have been described on goats in commercial farming systems in South Africa but not from flocks on communal grazing. During a longitudinal survey on the causes of goat kid mortality, conducted in Jericho district, North West Province, lice were collected from communally grazed indigenous goats. These lice were prepared for and viewed by scanning electron microscopy, and micromorphological taxonomic details are described. Three species of lice were found in the study area and identified as Bovicola caprae, Bovicola limbatus and Linognathus africanus. Sucking and biting lice were found in ten of the 12 herds of goats examined. Lice were found on both mature goats and kids. Bovicola caprae and $L$. africanus were the most common biting and sucking lice respectively in all herds examined. Scanning electron microscopy revealed additional features which aided in the identification of the louse species. Photomicrographs were more accurate aids to identification than the line drawings in the literature and facilitated identification using dissecting microscope.
\end{abstract}

Keywords: Bovicola spp., goat, lice, Linognathus africanus, scanning electron microscope

\section{INTRODUCTION}

Lice are divided into sucking and biting species (Anoplura: Linognathidae and Ischnocera: Trichodectidae). Both biting and sucking lice are ectoparasites that adversely affect low productivity in goats (Pandita \& Ram 1990). The actual loss resulting from louse infestation of goats is not easy to quantify but it was estimated to be UD\$800 000 in the USA (Steelman 1976). Zumpt (1970) describes losses in sheep during winter on the highveld

Department of Paraclinical Sciences, Faculty of Veterinary Science, University of Pretoria, Private Bag X04, Onderstepoort, 0110 South Africa

2 Department of Anatomy, Medical University of Southern Africa, Box 232, MEDUNSA, 0204 South Africa

3 Electron Microscope Unit, Medical University of Southern Africa, Box 232, MEDUNSA, 0204 South Africa

Accepted for publication 23 October 2003-Editor regions in South Africa and O'Callaghan, Beveridge, Barton \& McEvan (1989) describe the effects of experimental infestations with Linognathus vituli on undernourished calves. Unhygienic conditions, increased population density and inadequate housing promote the spread of louse infestations. Infestation can result in anaemia, hypoproteinaemia, secondary infestation, nutritional deficiencies and reduced vigour as well as in bacterial or fungal infections of bite wounds (Howell, Walker \& Nevill 1978; Pandita \& Ram 1990; Oberem \& Schröder 1993). In South Africa infestations with Linognathus africanus (the blue sucking louse of goats) and Bovicola limbatus (the red biting louse of goats) have been described in a commercial herd of Angora goats in the Eastern Cape Province (Horak, Mclvor \& Greeff 2001).

Scanning electron microscopic descriptions of lice have rarely been made. Previously morphological 
features used for the taxonomic differentiation of lice species were described using the standard light microscope (Green, Turner \& Sebei 2001; Turner, Baker \& Marais 2002). Light microscopy does not show in sufficient detail the morphology required for their classification. Because the taxonomic differences between Bovicola caprae and B. limbatus are based on the structure of their genital organs it has led to difficulty in identifying these louse species from the field.

\section{MATERIALS AND METHODS}

During a longitudinal survey on the causes of mortalities in goat kids in the Jericho district, North West Province, South Africa (Sebei 2002), live lice were collected from 12 herds of communally grazed indigenous type goats. As lice can easily be seen with the naked eye when the fleece is parted (Zumpt 1970) goats were visually and manually examined for external parasites in the coat of the animal. Areas sampled were the dorsal neck from behind the ear, tail area, back and rump, flanks, the dewlap/brisket area, buttock and the midline laterally (Price \& Graham, 1997). Live lice were collected by means of forceps dabbed in $70 \%$ alcohol and were then preserved in $70 \%$ alcohol. Fixed specimens were inspected under a dissection microscope. Undamaged adult males and females were selected for scanning electron microscopy (SEM), which has successfully been used for the identification of lice (Green \& Baker 1996; McCrindle, Green \& Bryson 1999; Turner et al. 2002). Lice were processed for SEM using the method described by Turner et al. (2002). A structured interview with the farmers was conducted in order to evaluate the stock management practices (including dipping) they used.

\section{RESULTS}

It was found that $83 \%(n=10)$ of the herds investigated $(n=12)$ were infested with biting and/or sucking lice. Three species of lice were found, namely $B$. caprae, $B$. limbatus and $L$. africanus (Table 1). Lice were found on both mature goats and kids. Bovicola caprae and $L$. africanus were the most common biting and sucking lice respectively in the herds examined.

Five species of lice have been described on goats throughout the world (Price \& Graham 1997), but no records could be found of simultaneous infestations by three or more species. Horak et al. (2001)
TABLE 1 Distribution of lice in different herd

\begin{tabular}{|c|l|l|l|}
\hline $\begin{array}{l}\text { Farmer } \\
\text { code }\end{array}$ & $\begin{array}{l}\text { Bovicola } \\
\text { caprae }\end{array}$ & $\begin{array}{l}\text { Bovicola } \\
\text { limbata }\end{array}$ & $\begin{array}{l}\text { Linognathus } \\
\text { africanus }\end{array}$ \\
\hline 1 & Negative & Negative & Negative \\
2 & Positive & Negative & Positive \\
3 & Positive & Negative & Negative \\
4 & Negative & Negative & Positive \\
5 & Positive & Positive & Positive \\
6 & Positive & Positive & Positive \\
7 & Positive & Negative & Positive \\
8 & Positive & Negative & Positive \\
9 & Positive & Positive & Positive \\
10 & Positive & Negative & Positive \\
11 & Negative & Negative & Negative \\
12 & Positive & Positive & Positive \\
\hline
\end{tabular}

have found mixed infestations of $B$. limbatus and $L$. africanus. In this study two species of biting lice (Fig. 1 and 2) and one species of sucking louse (Fig. 3) infested one herd, and all three species were collected from individual goats in the herd. For epidemiological studies it was necessary to accurately identify these three species. O'Callaghan et al. (1989) specifically mentioned difficulties in identifying species on goats using the line-drawings made from light microscopy that are available in the literature. Distinguishing micro-morphological features used for species identification under SEM are shown (Fig. 1-12).

The sucking louse was identified as $L$. africanus by the following characteristics which distinguish it from Linognathus stenopsis (O'Callaghan et al. 1989). The shape of the head, with the prominent bulging ocular points posterior to the antenna, is typical and was confirmed by SEM (Fig. 3), together with the rounded female gonopods (Fig. 5) (Ferris 1951; Kim, Pratt \& Stojanovich 1986). The female terminal gonopod of $L$. africanus is rounded and lacks the "tooth-like" process described for $L$. stenopsis (Kim et al. 1986). The gonopods of the male included a pair of terminal tubercles with setae (Fig. 6) and are characteristic of $L$. africanus (Price \& Graham 1997).

Differentiating between the Bovicola spp. was more difficult as the adult females are difficult to separate (Price \& Graham 1997). None of the Bovicola spp. were densely covered with setae or large enough to be identified as Bovicola crassipes which is one of the three Bovicola spp. infesting goats (Ledger 1980). Under the stereoscopic microscope the males of $B$. caprae and $B$. limbatus were only distinguishable by the number of sclerotized sternites (Ledger 1980). All the paratergites of both sexes of 


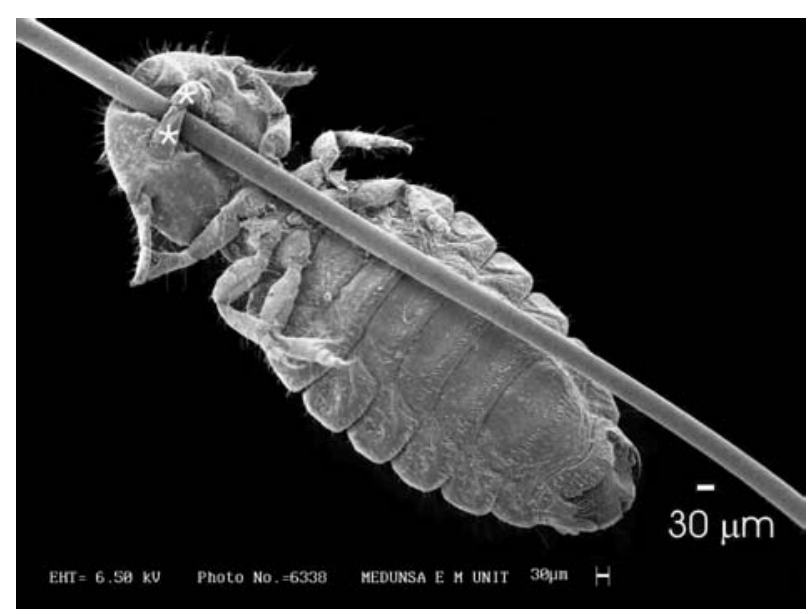

FIG. 1 Ventral surface of Bovicola caprae attached to a hair by paired mandibles $\left({ }^{*}\right)$

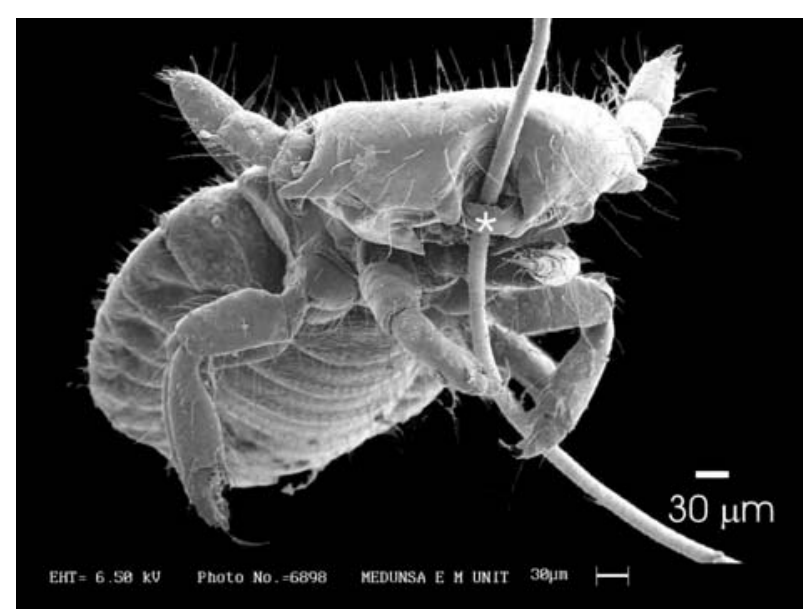

FIG. 2 Anteroventral surface of Bovicola limbatus showing mandibles $\left(^{*}\right)$ and tarsal claws

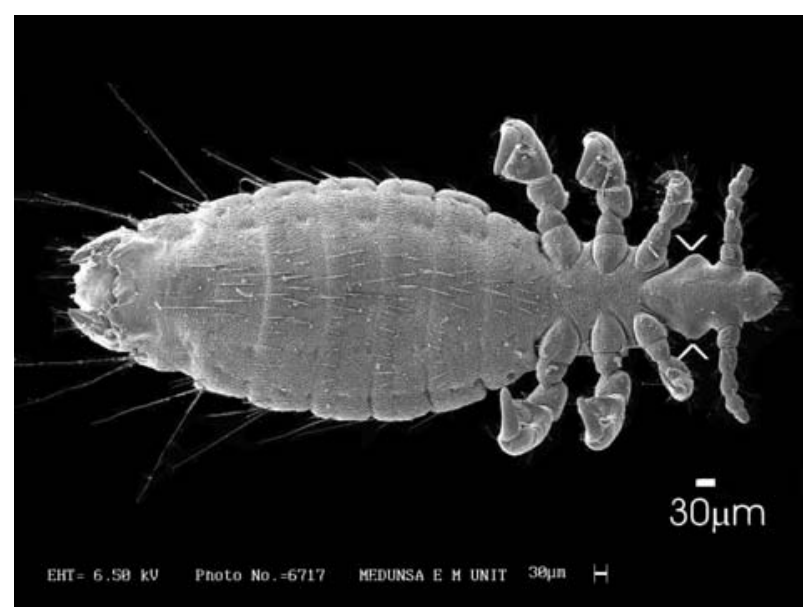

FIG. 3 Ventral view adult female Linognathus africanus showing prominent ocular processes $(<<)$ on head and legs ending in large single claws

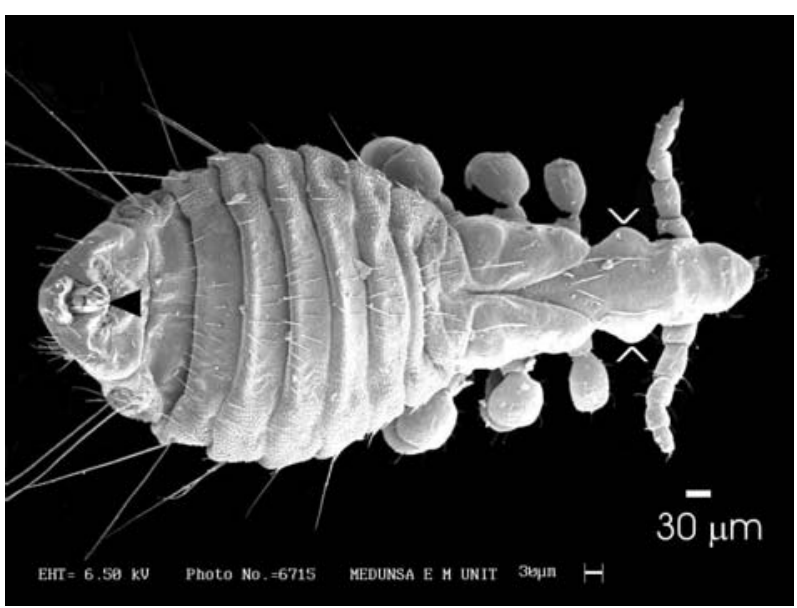

FIG. 4 Dorsal view of adult male Linognathus africanus showing ocular processes $(<<)$ on the head and pseudopenis (black arrow on abdomen)

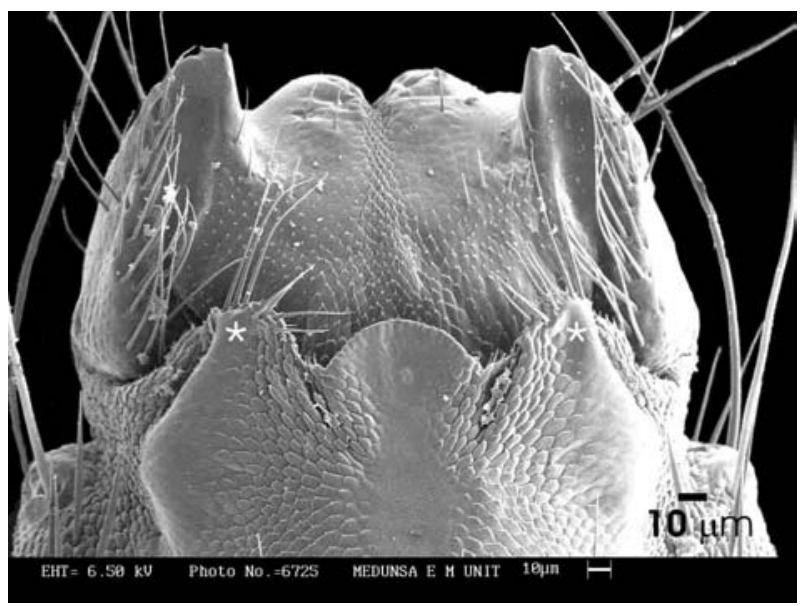

FIG. 5 Ventral view of the female gonopods of Linognathus africanus which lacks the apical tooth at $\left(^{*}\right)$ as found in Linognathus stenopsis

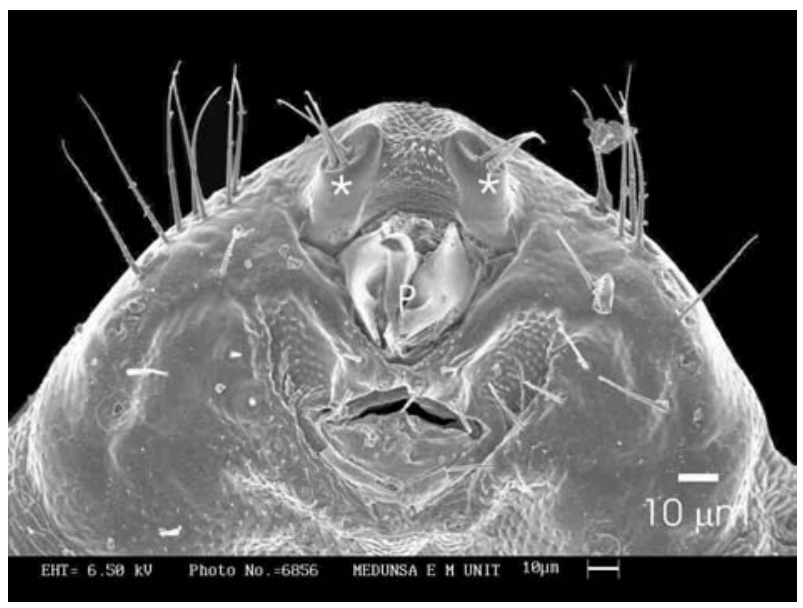

FIG. 6 Ventral view of male gonopods of Linognathus africanus showing the tubercles $\left(^{*}\right)$ and pseudopenis (P) 


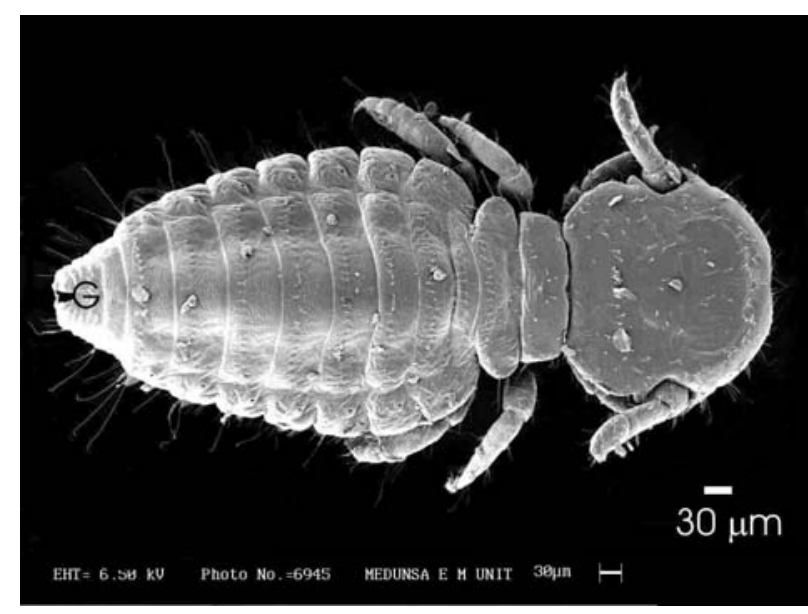

FIG. 7 Dorsal view of male Bovicola limbatus showing the conical male gonopods $(G)$

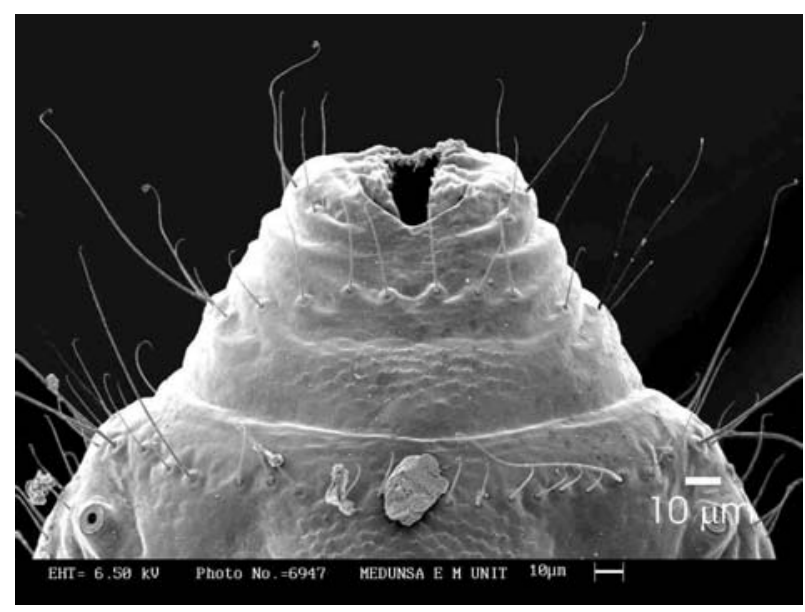

FIG. 8 Enlarged view of the conical male gonopods of Bovicola limbatus showing the characteristic long setae

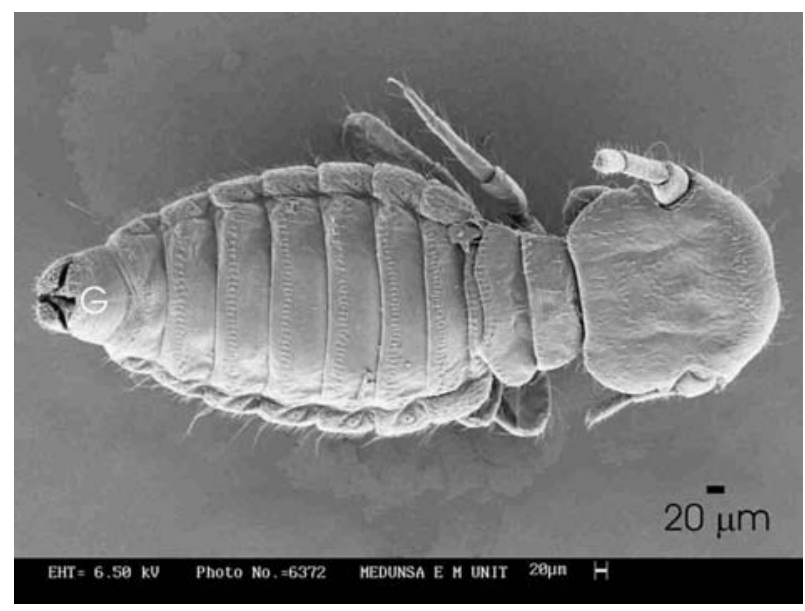

FIG. 9 Dorsal view of male Bovicola caprae showing the conical male gonopods $(G)$

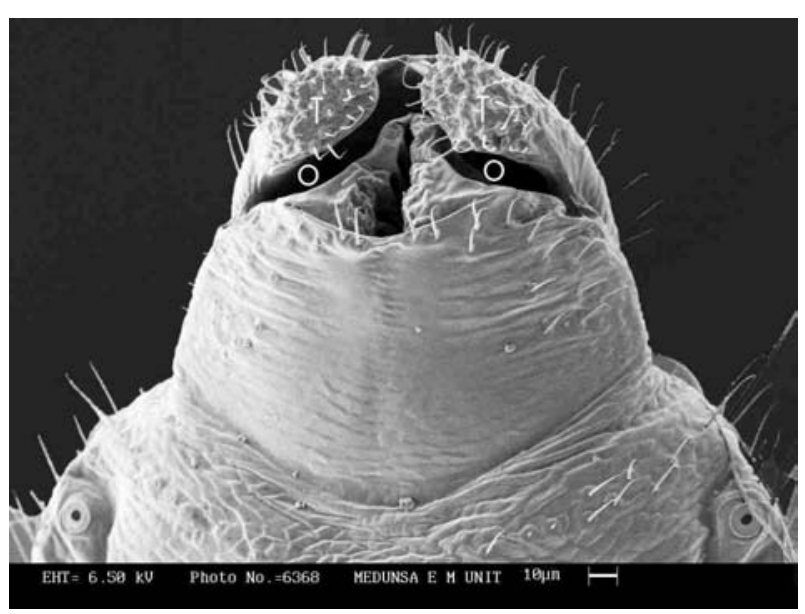

FIG. 10 Enlarged view of the conical male gonopods of Bovicola caprae showing the terminal flaps $(T)$ covered with short setae closing the genital opening $(\mathrm{O})$

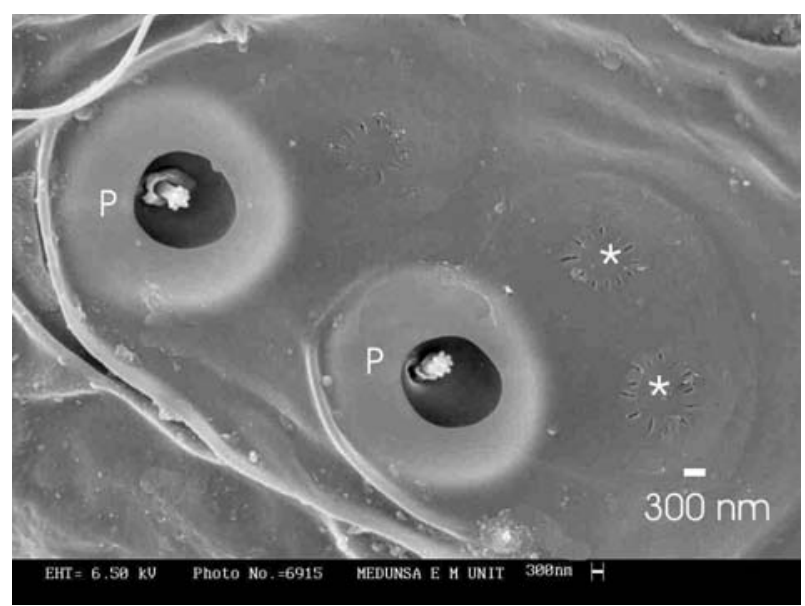

FIG. 11 Enlarged view of the antennal sensilla coeloconica of Bovicola caprae showing the two pore organs with the tuft organs $(P)$ and two plates organs enclosed in a single plate $\left(^{*}\right)$

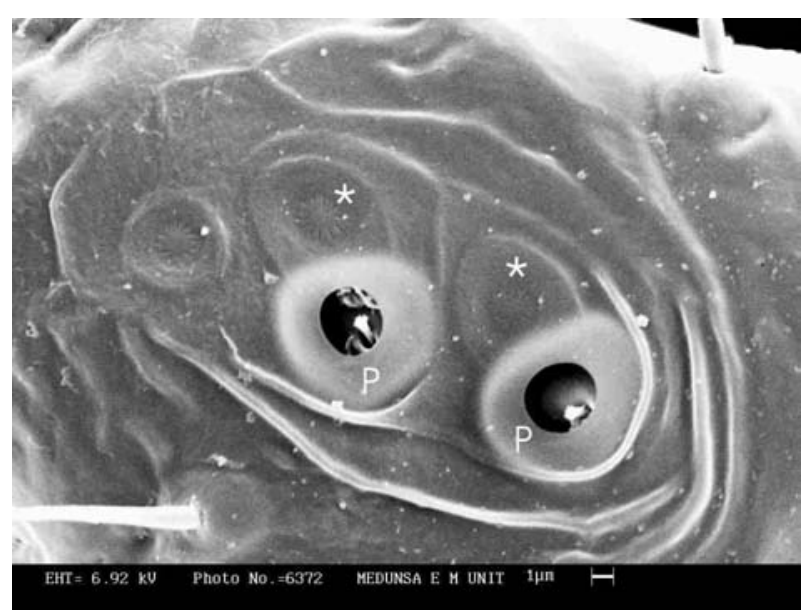

FIG. 12 Enlarged view of the antennal sensilla coeloconica of Bovicola caprae showing the two pore organs with the tuft organs $(P)$ and three plate organs each enclosed in their own plates $\left(^{*}\right)$ 
B. caprae were well-sclerotized and brown in colour while in $B$. limbatus only the anterior two paratergites were sclerotized in both sexes. These paratergites were not previously identifiable from the line drawings published in the literature (Werneck 1950). However, once accurate micro-morphology was determined by SEM, the two species could easily be differentiated under the stereoscopic microscope.

According to Price \& Graham (1997) B. caprae and $B$. limbatus can be differentiated only by examining the genitalia. The male gonopods of both species, when viewed under low magnification, are conical in shape (Fig. 7-9). This was confirmed with SEM. The conical gonopods of $B$. limbatus have scattered long setae (Fig. 8) while the posterior end of the gonopods of $B$. caprae are densely covered with short setae (Fig. 10). The distinctive characteristic of $B$. caprae is the presence of two terminal flaps, which close over the genital opening (Fig. 10).

The antennal sensilla coeloconica were similar in both species with two pore organs each containing a tuft organ (Fig. 11-12). The three adjacent plate organs, however, were different. In B. limbatus the anterior three plate organs share one plate (Fig. 11) while the two plate organs in $B$. caprae are each surrounded by their own plate (Fig. 12) (Ferris 1951; Miller \& Frederick 1971).

\section{DISCUSSION}

The main aim of this investigation was to study by SEM the micro-morphological features which could aid in identification or differentiation of louse species found on communally grazed goat herds. Micrographs illustrating taxonomic morphological differences between $B$. limbatus, $B$. caprae and $L$. africanus show details of micro-morphology not obvious under the light microscope. The differences between morphological features seen in micrographs obtained from SEM and the line drawings seen in the literature could be attributed to the difference in the resolution power of light and electron microscopes (Green et al. 2001; Turner et al. 2002), and SEM thus allowed for more accurate species identification. Once positively identified by SEM, it was found that specimens of $B$. caprae could also be distinguished from $B$. limbatus under the stereoscopic microscope on the basis of colour. This will be useful for field studies of the epidemiology of two the species. Micrographs obtained using SEM can be used to update the literature references used for the identification of these lice spe- cies. Many of the line drawings, which are currently the only taxonomic references, were published in obscure journals, textbooks and memoirs of many years ago (Werneck 1950; Ferris 1951; Kim et al. 1986).

Although the three goat louse species identified in this study have been recorded from commercial goat production systems, this is the first record from goats in a communal grazing system. According to Seddon (1967) lice infestation occurs more frequently on young animals. This was also the case in this study. Probably as a result of better identification of lice species due to use of SEM, it was found that all three species could infest a single animal,. Mixed infestations, by all three species of lice, were also found in a single herd. No records could be found in the literature that mixed infestations by different species of red biting lice occur. This may be due to the limited resolution obtained by light microscopy and the fact that morphological differences can only be distinguished on male specimens.

\section{ACKNOWLEDGEMENTS}

We extend our sincere gratitude to the farmers for allowing us to handle their goats and collect specimens from them and also for their patience and hospitality during the survey. The National Research Foundation is thanked for financial support.

\section{REFERENCES}

FERRIS, G.F. 1951. The sucking lice. Volume 1. Memoirs of the Pacific Coast Entomological Society. San Francisco: Pacific Coast Entomological Society, 223-225.

GREEN, E.D. \& BAKER, C. 1996. Observations on the micromorphology of tropical rat mite Ornithonyssus bacoti (Hirst) as revealed by scanning microscopy. Journal of the South African Veterinary Association, 67:128-132.

GREEN, E.D., TURNER, M.L. \& SEBEI, P.J. 2001. Functional morphology of the goat biting louse (Bovicola caprae). Proceedings of the Microscopy Society of Southern Africa, 31: 62.

HORAK, I.G., MACIVOR, K.M. DE F. \& GREEF, C.J. 2001. Parasites of domestic and wild animals in South Africa. XXXIX. Helminth and arthropod parasites of Angora goats in the southern Karoo. Onderstepoort Journal of Veterinary Research, 68:27-35.

HOWELL, C.J., WALKER, J.B. \& NEVILL, E.M. 1978. Ticks, mites and insects infesting domestic animals in South Africa. Part 1. Descriptions and biology. Department of Agricultural Technical Services, Republic of South Africa (Science Bulletin, No. 393).

KIM, K.C., PRATT, H.D. \& STOJANOVICH, C.J. 1986. The sucking lice of North America: An illustrated manual. University Park and London: Pennsylvania State University Press. 
LEDGER, J.A. 1980. The arthropod parasites of vertebrates in Africa south of the Sahara. Volume IV. Phthiraptera (Insecta). Publications of the South African Institute for Medical Research, No. 56:255-257.

McCRINDLE, C.M.E., GREEN, E.D. \& BRYSON, N.R. 1999. A primary animal health care approach to treatment and control of flea (Ctenocephalides felis) infestation in indigenous goats kept on communal grazing. Journal of the South African Veterinary Association, 70:21-24.

MILLER, J.R. \& FREDERICK, H. 1971. Antennal sensilla coeloconica of Pedicinus obtusus obtusus. Annals of the Entomological Society of America, 64:973-975.

OBEREM, P.T. \& SCHRÖDER, J. 1993. Ecto- and endoparasites, in Livestock Production Systems-Principles and Practice, edited by C. Maree \& N.H. Casey. Brooklyn: AgriDevelopment Foundation: 334-360.

O'CALLAGHAN, M.G., BEVERIDGE, I, BARTON, M.A. \& McEVAN, D.R. 1989. Recognition of the sucking louse, Linognathus africanus, on goats. Australian Veterinary Journal, 66:228-229.

PANDITA, N.N. \& RAM, S. 1990. Control of ectoparasitic infestation in country goats. Small Ruminant Research, 3:403-412.
PRICE, M.A. \& GRAHAM, O.H. 1997. Chewing and sucking lice as parasites of mammals and birds. United States Department of Agriculture (Agricultural Research Service Technical Bulletin, No.1849).

SEBEI, P.J. 2002. The assessment of some factors influencing the survival of kids in a small-scale communal goat production system. MSc thesis, University of Pretoria.

SEDDON, H.R. 1967. Diseases of domestic animals in Australia, Part 2, Arthropod infestations (flies, lice and fleas), $2^{\text {nd }}$ ed. Commonwealth of Australia (Service publications, No. 6).

STEELMAN, C.D. 1976. Effects of external and internal arthropods parasites on domestic livestock production. Annual Review of Entomology, 21:155-178.

TURNER, M.L., BAKER, C. \& MARAIS, R. 2002. Scanning electron microscopical investigation of the waterbuck louse Bovicola (syn. Damalinia) hilli found at the Rietvlei Nature Reserve near Pretoria. Koedoe, 45:59-63.

WERNECK, F.L. 1950. Os malófagos de mamíferos, Parte II: Ischnocera (continuaçao de Trichodectidae) e Rhynchopthirina. Memorias do Instituto Oswaldo Cruz, 5:1-207

ZUMPT, G.F. 1970. Observations on red lice (Damalinia ovis) infestations in sheep on the Transvaal Highveld. Journal of the South African Veterinary Medical Association, 41:315317. 